Research Article

\title{
Sleep Quality's Effect on Vigilance and Perceptual Ability in Adolescent and Adult Athletes
}

\author{
Vasileios T. Stavrou $\mathbb{D}^{1,}{ }^{1,2}$ Kyriaki Astara ${ }^{1},{ }^{1}$ Konstantinos N. Tourlakopoulos $\mathbb{D}^{1}{ }^{1}$ \\ Zoe Daniil $\mathbb{D}$, ${ }^{1}$ Konstantinos I. Gourgoulianis $\mathbb{D}^{1},{ }^{1}$ Konstantinos Kalabakas $\mathbb{D}^{2}{ }^{2}$ \\ Dimitrios Karagiannis $\mathbb{D}^{2}$, and George Basdekis $\mathbb{D}^{2}$ \\ ${ }^{1}$ Laboratory of Cardio-Pulmonary Testing and Pulmonary Rehabilitation, Department of Respiratory Medicine, \\ Faculty of Medicine, University of Thessaly, Larissa, Greece \\ ${ }^{2}$ The Medical Project, Prevention, Evaluation and Recovery Center, Larissa, Greece
}

Correspondence should be addressed to Vasileios T. Stavrou; vasileiosstavrou@hotmail.com

Received 18 January 2021; Revised 21 March 2021; Accepted 24 March 2021; Published 12 April 2021

Academic Editor: Ian L. Swaine

Copyright (c) 2021 Vasileios T. Stavrou et al. This is an open access article distributed under the Creative Commons Attribution License, which permits unrestricted use, distribution, and reproduction in any medium, provided the original work is properly cited.

\begin{abstract}
The aim of the study was to investigate the effect of sleep quality in cognitive domains of perceptual ability after exhausting exercise in adolescent and adult athletes. Eighty-six male professional soccer players were included in our study and divided into two groups: adolescents (age: $17.3 \pm 0.2$ yrs, body mass: $68.9 \pm 7.9 \mathrm{~kg}$, body fat: $9.9 \pm 3.6 \%$ ) versus adults (age: $26.3 \pm 5.2 \mathrm{yrs}$, body mass: $76.5 \pm 7.2 \mathrm{~kg}$, body fat: $10.3 \pm 3.1 \%$ ). For each athlete, prior to cardiopulmonary exercise testing (CPET), anthropometric and morphological characteristics were recorded and Pittsburgh Sleep Quality Index (PSQI) questionnaire was answered. Immediately after CPET, all athletes underwent the perceptual ability test (PATest) for $30 \mathrm{sec}$ and the sum of hits (rep/30 sec) and the time between a visual stimulus and the following stimulus (mean reaction time; RT, sec) were recorded. Oxygen uptake in maximal effort and in anaerobic threshold showed differences between hits $(P=0.037)$ and RT $(P=0.025)$. The variable of PSQI questionnaire "had bad dreams" showed correlation with hits $(P=0.021)$ and RT $(P=0.011)$ and the RT showed correlation with variables "cannot breathe comfortably" $(P=0.041)$ and "...enthusiasm to get things done" $(P=0.041)$. Adolescents showed poorer sleep quality (PSQI score: $5.7 \pm 3.6$ vs. $2.4 \pm 2.6)$ compared to adults and slower reaction time $(0.9 \pm 0.1 \mathrm{vs.} 0.8 \pm 0.1 \mathrm{sec}, P=0.029)$ compared to adolescent athletes with PSQI score $\geq 5.5$. The variable of PSQI score in adolescents is related to HR in maximal effort $(r=-0.364, P=0.032)$ and in adults is related to speed $(r=-0.335, P=0.016)$. Perceptual ability, which requires sustained attention, vigilance, and motor coordination, is often negatively affected by restricted sleep, especially in adolescents.
\end{abstract}

\section{Introduction}

Soccer is one of the most popular team sports practiced around the world. During the season, elite male soccer players practice on a daily basis, often twice a day, play one or two matches per week, and take part in national and/or international tournaments [1]. This schedule requires well developed physical, mental, and physiological characteristics [1] and optimal recovery to reduce the risk of transitioning into a state of excessive fatigue as well as to reduce the risk of injury [2].

Sleep quality, in high level athletes, is affected by the kind of sport, the type of exercise, the training frequency, psychobiological mechanisms, and chronotype [3]. Adequate sleep is essential for peak performance while sleep deprivation (SD) has been shown to negatively affect many physiological, cognitive, and behavioral measures [4] and associated with longer reaction times and reduced force on a simple and choice reaction time test (Baseline: $244 \pm 39$ versus SD: $281 \pm 31 \mathrm{~ms}$ ) [5]. Moreover, sleep deprivation reduces the fitness indicators (such as $V \mathrm{O}_{2 \max }$ ) without affecting anaerobic power as recording after Wingate test [6]. Athletes with poor sleep quality and quantity have higher levels of confusion compared to athletes reporting better sleep, while the athletes who usually lose in team 
sports have higher levels of tension and confusion before the game [7]. Enhancing sleep quality and quantity is a fundamental tool to promote multidimensional recovery for athletes, in the context of maintaining physical condition and alertness [2]. However, alertness is only one of the several cognitive functions that are all neurally interlinked and thus hindered by sleep deprivation [8]. Perceptual functions, as a whole, have not been adequately studied in relation to exercise and sleep characteristics. To this end, we designed this study to investigate the effect of sleep quality in several cognitive components of perceptual ability after exhausting exercise between adolescents and adults. We hypothesized that quality and quantity of sleep could affect the fitness indicators and parameters of perceptual ability.

\section{Methods}

2.1. Participants. Eighty-six Greek male professional soccer players (age, $22.7 \pm 6.0 \mathrm{yrs}$, training age, $9.3 \pm 4.9 \mathrm{yrs}$, body fat, $10.1 \pm 3.3 \%$, Table 1), from the Greek Super League 1 and 2 , were included in our study on a voluntary basis, during preparation period between July 2019 and August 2019 and two months before the official games started. All athletes were divided into two groups: adolescents ( $\leq 18$ years old) versus adults ( $>18$ years old) Table 1 . Inclusion criteria were age between $<15$ and $>35$ years old, training age $\geq 4$ years ( $\geq 600$ min per week with $\mathrm{HR} \geq 70 \%$ of $\max$ ), and not having a recent injury (for the last 12 months) [9]. All volunteers have lived and been trained in less than $100 \mathrm{~m}$ altitude at sea level, for above 10 months [10]. The study was conducted according to the Helsinki declaration for use in Human subjects ( $\mathrm{N}^{\circ}$ 58076/14-11-2018, Scientific Council of University Hospital of Larissa, Greece) and personal data [137/ A/29-8-2019 and EC 2016/679] according to European Parliament and of the Council of the European Union. All the participants, coaches, team chiefs, and parents submitted a written consent.

2.2. Procedures. For each athlete, prior to cardiopulmonary exercise testing (CPET), anthropometric and morphological characteristics (Table 1) and body composition (Tanita MC980, Illinois, USA) were recorded. All athletes answered Pittsburgh Sleep Quality Index (PSQI) questionnaire $[9,11]$ and it was recorded in their medical history.

CPET was performed on an electronic treadmill ergometer (Cosmos LE 100CE-720CE, Germany). For each athlete, $\mathrm{O}_{2}$ uptake (FitmateMED Cosmed, Italy) and heart rate (Garmin, Kansas, USA) were recorded during CPET (Table 1). Prior to testing, all athletes were familiarized with the test via a $2 \mathrm{~min}^{-1}$, in resting and upright position $\left(1^{\text {st }}\right.$ stage). In 2nd stage, all athletes started the test with speed $5 \mathrm{~km} / \mathrm{h}^{-1}$ and increment $1 \mathrm{~km}$ per $\min ^{-1}$, until exhausting. After the end of the maximal effort ( $2^{\text {nd }}$ stage), they performed a $5 \mathrm{~min}^{-1}$ walking ( $3^{\text {rd }}$ stage) for recovery purposes, with speed $3 \mathrm{~km} / \mathrm{h}^{-1}$ [12]. The slope of the treadmill during CPET was steadily $1 \%$.

Immediately after CPET, all athletes underwent the perceptual ability test (PATest) to evaluate the accuracy to visual stimulus by Fitlight Trainer $^{\circledR}$ test. The Fitlight Trainer ${ }^{\circledR}$ (FitLight Sports Corp, Canada; available in Greece by Serinth ${ }^{\circledR}$ ) is a wireless reaction system comprised of four LED lights controlled by a tablet computer. The lights have an inbuilt sensor which reacts proximity or touch and deactivates the light [13]. Four lights positioned on the floor were used as stimulus (Figure 1) and turning off the lights was done with feet. The frequency between signals was $2 \mathrm{sec}$. All athletes did one trial for $30 \mathrm{sec}$ and recorded the sum of hits $(\mathrm{rep} / 30 \mathrm{sec})$ and the time interval between a visual stimulus and the following stimulus (mean reaction time; RT, sec). None of the participants stated they had previous experience in this test, so learning effect does not exist.

All sessions were performed in The Medical Project Center, Larissa, Greece, with environmental temperature at $22 \pm 1^{\circ} \mathrm{C}$ and humidity $45 \pm 3 \%$. The evaluation was made between 10:00 a.m. and 15:00 p.m. and all athletes did not have a previous exercise and/or training for 48 hours.

2.3. Statistical. Kolmogorov-Smirnov test was utilized to assess normality of distribution of values. Spearman's Rho and Pearson's R correlation coefficients were used to determine correlations between continuous variables where appropriate. Independent samples $t$-tests and Mann-Whitney $U$-test were used to compare rates of change for adolescents ( $\leq 18$ years old) and adults ( $>18$ years old) and cross-sectional point in PSQI score 5.5 was used to separate good versus bad sleepers [3]. Regression analysis was performed for multivariate adjustments for all covariates, simultaneously. For all aforementioned tests, a $P$ value $<0.05$ was considered statistically significant and the data are presented as mean value, standard deviation (mean $\pm \mathrm{SD}$ ), and $95 \%$ confidence intervals. The SPSS 25 statistical package (SPSS Inc., Chicago, Illinois, USA) was used for the statistical analyses.

\section{Results}

3.1. Cardiopulmonary Exercise Testing. Results showed differences between fitness indicators and PATest (Table 1). Oxygen uptake in maximal effort $\left(V \mathrm{O}_{2 \max }\right.$, $\left.58.1 \pm 4.9 \mathrm{ml} / \mathrm{min}^{-1} / \mathrm{kg}^{-1}\right)$ showed statistical significance with Hits $(r=-0.279, P=0.037)$ and RT $(r=-0.365$, $P=0.025)$ and oxygen uptake in anaerobic threshold $\left(45.2 \pm 4.2 \mathrm{ml} / \mathrm{min}^{-1} / \mathrm{kg}^{-1}\right)$ showed statistical significance with Hits $(r=0.397, P=0.042)$ and RT $(r=0.389$, $P=0.026)$. Moreover, $V \mathrm{O}_{2 \max }$ showed statistical significance with PSQI parameter "cannot breathe comfortably" $(r=0.241, P=0.025)$ and $V \mathrm{O}_{2}$ in anaerobic threshold, as a percent of maximal uptake $\left(V_{2}\right.$ anaerobicthreshold: $77.8 \pm 5.5 \%$ of $\max$ ), with parameters of PSQI "cannot get to sleep within 30 minutes" $(r=0.281, P=0.009)$, "cough or snore loudly" $(r=0.293, P=0.006)$, and PSQI score $(r=0.254, P=0.019)$. Adolescents showed lower values in parameters of $V \mathrm{O}_{2 \text { anaerobicthreshold }}(46.4 \pm 4.6$ vs. $44.3 \pm 3.7 \mathrm{ml} / \mathrm{min}^{-1} / \mathrm{kg}^{-1}, \quad 95 \%$ CI: 0.321 to 3.902 , $\left.t_{(84)}=2.345, \quad P=0.021\right), \quad V \mathrm{O}_{2 \max } \quad(59.7 \pm 6.2 \quad$ vs. $57.0 \pm 3.6 \mathrm{ml} / \mathrm{min}^{-1} / \mathrm{kg}^{-1} \quad 95 \%$ CI: 0.618 to 4.801 , 


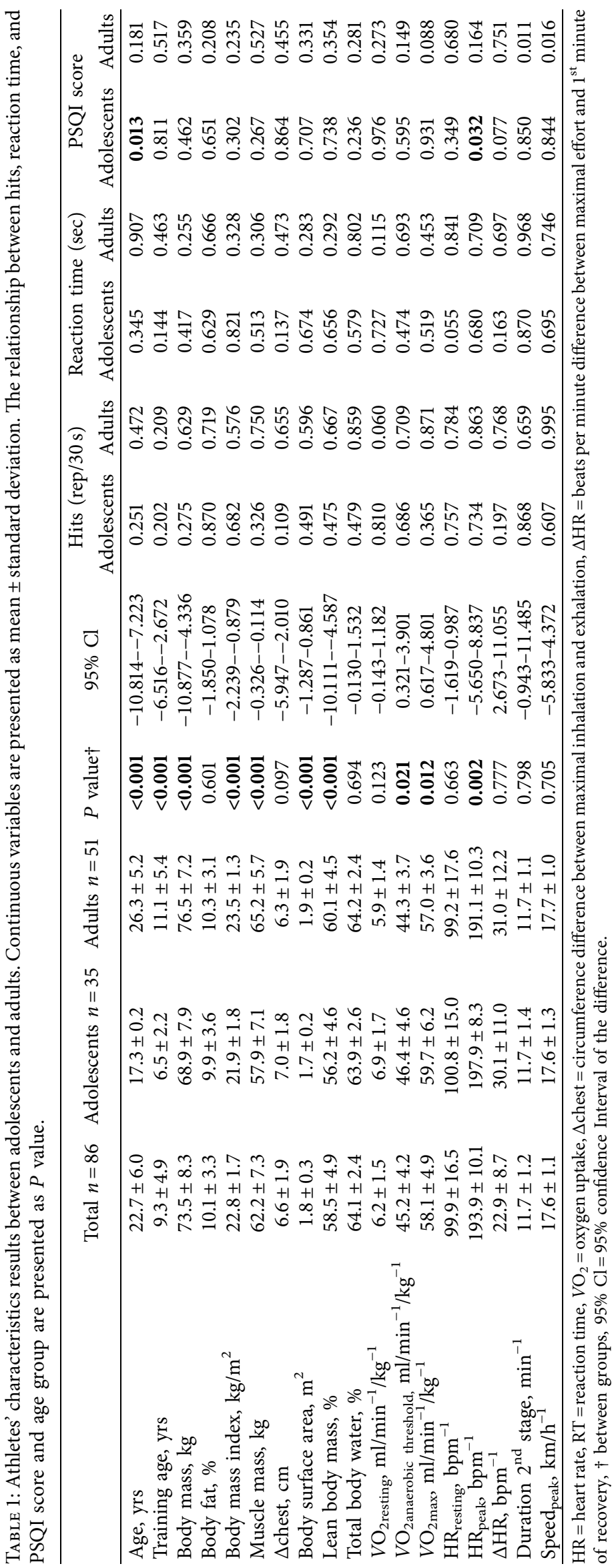






Figure 1: Dimensions of Fitlight Trainer ${ }^{\circledast}$ during PATest.

$\left.t_{(84)}=2.576, P=0.012\right)$ and higher values in $\mathrm{HR}$ in maximal effort $(197.9 \pm 8.3$ vs. $191.1 \pm 10.3 \mathrm{bpm}, 95 \% \mathrm{CI}$ : 2.673 to $\left.11.055, t_{(84)}=3.257, P=0.002\right)$ compared to adults. The variable of PSQI score in adolescents was related to $\mathrm{HR}$ in maximal effort $(r=-0.364, P=0.032)$ and in adults was related to duration $(r=-0.352$, $P=0.011)$ and speed $(r=-0.335, P=0.016)$.

3.2. Sleep Quality. Results showed differences between age groups and PSQI variables (Table 2). Adolescents showed poorer sleep quality compared to adults (Figure 2). More specifically, adolescents scored higher in variabilities "wake up in the middle of the night or early morning" (1.5 $\pm 1.1 \mathrm{vs.}$ $0.6 \pm 0.9,95 \% \mathrm{CI}: 0.378$ to $\left.1.242, t_{(84)}=3.728, P<0.001\right)$, "have to get up to use the bathroom" $(1.1 \pm 0.9$ vs. $0.6 \pm 0.8$, 95\% CI: 0.153 to $\left.0.938, t_{(84)}=2.762, P=0.007\right)$, "cannot breathe comfortably" $(0.1 \pm 0.4$ vs. $0.1 \pm 0.1,95 \% \mathrm{CI}: 0.002$ to $\left.0.226, t_{(84)}=2.042, P=0.046\right)$, "cough or snore loudly" $\left(0.3 \pm 0.7\right.$ vs. $0.1 \pm 0.2,95 \%$ CI: 0.041 to $0.470, t_{(84)}=2.364$, $P=0.020)$, "feel too hot" $(1.1 \pm 1.0$ vs. $0.4 \pm 0.8,95 \%$ CI: 0.309 to $\left.1.153, t_{(84)}=3.442, P=0.001\right)$, "have bad dreams" $\left(0.4 \pm 0.7\right.$ vs. $0.1 \pm 0.4,95 \%$ CI: 0.074 to $0.566, t_{(84)}=2.584$, $P=0.012)$, “. . how often have you had trouble staying awake while..." $(0.3 \pm 0.6$ vs. $0.1 \pm 0.2,95 \% \mathrm{CI}: 0.023$ to 0.373 , $\left.t_{(84)}=2.253, P=0.027\right)$, and “. .enthusiasm to get things done" $(0.4 \pm 0.6$ vs. $0.1 \pm 0.4,95 \% \mathrm{CI}: 0.075$ to 0.507 , $\left.t_{(84)}=2.679, P=0.009\right)$ compared to adults. Adolescents showed correlation with reaction time in PSQI variables "cannot breathe comfortably" $(r=0.410, P=0.014)$ and "have bad dreams" ( $r=0.357, P=0.035)$. The athletes with PSQI score $\geq 5.5$ were younger $(19.3 \pm 4.0$ vs. $24.3 \pm 6.2 \mathrm{yrs}$, $95 \% \mathrm{CI}:-7.523$ to $\left.-2.386, t_{(84)}=-3.836, P<0.001\right)$ and had lower training age $(7.6 \pm 3.7$ vs. $10.1 \pm 5.3$ yrs, $95 \% \mathrm{CI}:-4.618$ to $\left.-0.199, t_{(84)}=-2.169, P=0.033\right)$. Moreover, athletes with PSQI score $\geq 5.5$ showed lower reduction of $\mathrm{HR}$ at the first minute of recovery stage $(28.2 \pm 11.7$ vs. $35.6 \pm 9.9 \mathrm{bpm}, 95 \%$ CI: 3.239 to $\left.12.836, t_{(84)}=2.867, P=0.005\right)$ and lower reaction time $(0.9 \pm 0.2$ vs. $0.8 \pm 0.9 \mathrm{sec}, 95 \% \mathrm{CI}: 0.008$ to 0.137 , $\left.t_{(84)}=2.186 P=0.036\right)$, compared to athletes with PSQI score $<5.5$. In addition, the adolescent athletes with PSQI score $\geq 5.5$ displayed slower reaction time $(0.9 \pm 0.1$ vs. $0.8 \pm 0.1 \mathrm{sec}, 95 \%$ CI: 0.011 to $\left.0.203, t_{(33)}=2.277, P=0.029\right)$ compared to adolescent athletes with PSQI score $<5.5$. The adult athletes did not show significant differences by crosssectional point in PSQI score 5.5.
3.3. Perceptual Ability Test. Results showed a difference between variabilities during perceptual ability test (reaction time: $0.855 \pm 0.114 \mathrm{~s}$, Hits: $31.8 \pm 3.2 \mathrm{rep} / 30 \mathrm{~s}$ ). Athletes with lower reaction time showed higher count of hits on deactivating the light (Fitlight Trainer ${ }^{\circledR}$ ), compared to athletes with higher score on reaction time (Figure 3(a)) and athletes with poorer sleep quality had lower reaction time (Figure 3(b)). Moreover, the reaction time did not show significant differences between adolescents and adults (Figure 3(c)).

3.4. Athletes' Characteristics. Results showed differences between age groups and characteristics (Table 1). For the total of athletes, the variable muscle mass showed correlation with PSQI questionnaire variables "cannot get to sleep within 30 minutes" $(r=-0.268, \quad P=0.013)$, "feel too hot" $(r=-0.329, P=0.002)$, and "had bad dreams" ( $r=-0.320$, $P=0.003)$. The age showed correlation with PSQI questionnaire variables "cannot get to sleep within 30 minutes" $(r=-0.272, P=0.011)$, "wake up in the middle of the night" ( $r=-0.325, P=0.002)$, "cough or snore loudly" ( $r=-0.236$, $P=0.029)$, "feel too hot" $(r=-0.361, P=0.001)$, and "had bad dreams" $(r=-0.281, P=0.009)$. Adolescents showed lower values in parameters of body composition variabilities (body mass: $68.9 \pm 7.9$ vs. $76.5 \pm 7.2 \mathrm{~kg}, 95 \% \mathrm{CI}:-10.877$ to $-4.337, t_{(84)}=-4.426, P<0.001$; body mass index: $21.9 \pm 1.8$ vs. $23.5 \pm 1.3 \mathrm{~kg} / \mathrm{m}^{2}, 95 \% \mathrm{CI}:-2.239$ to $-0.879, t_{(84)}=-4.558$, $P<0.001$; muscle mass: $57.9 \pm 7.1$ vs. $65.2 \pm 5.7 \mathrm{~kg}, 95 \% \mathrm{CI}$ : -10.111 to $-4.587, t_{(84)}=-5.292, P<0.001$; body surface area: $1.7 \pm 0.2$ vs. $1.9 \pm 0.2 \mathrm{~m}^{2}, 95 \% \mathrm{CI}:-0.326$ to -0.115 , $t_{(84)}=-4.145, P<0.001$ and lean body mass: $56.2 \pm 4.6$ vs. $60.1 \pm 4.5 \%$, 95\% CI: -5.947 to $-2.010, t_{(84)}=-4.020$, $P<0.001$, Table 1 ) compared to adults (Table 1 ). The variable of age in adolescent group showed correlation with PSQI score $(r=-.418, P=0.013)$. The variable muscle mass in adolescent group showed correlation with PSQI questionnaire variable "cannot get to sleep within 30 minutes" $(r=-0.371, P=0.028)$. The variable of PSQI questionnaire "feel too hot" showed correlation, in adult group, with variable of body surface area $(r=-0.283, P=0.044)$ and lean body mass $(r=-0.281, P=0.046)$.

Multiple $\mathrm{R}$ of regression analysis was .91 which is statistical difference to zero, $F_{(21,64)}=13.771, P<0.001$. A total of $76 \%$ of the age of athletes was interpreted through variabilities: training age $(t=8.96, P<0.001)$, total body water $(t=-2.18, P=0.033)$, muscle mass $(t=2.66, P=0.010), \mathrm{HR}$ in maximal effort $(t=-2.45, P=0.017)$, and PSQI score $(t=-2.627, P=0.011)$.

\section{Discussion}

The data from the present study reveal an interrelationship among sleep quality, perceptual ability, and performance, which is more pronounced in adolescents. Sleep is a key component in an athlete's recovery process [9]. Sleep deprivation reflects symptoms of overtraining, both physical and mental, in periods of increasing training load, stress, and muscle and bone injuries [14]. Chronic and/or acute sleep 
TABLE 2: Analysis between PSQI results and age group. Continuous variables are presented as mean \pm standard deviation. The relationship between reaction time and age group is presented as $P$ value.

\begin{tabular}{|c|c|c|c|c|c|c|c|}
\hline & \multirow{2}{*}{$\begin{array}{c}\text { Total } \\
n=86\end{array}$} & \multirow{2}{*}{$\begin{array}{l}\text { Adolescents } \\
\quad n=35\end{array}$} & \multirow{2}{*}{$\begin{array}{c}\text { Adults } \\
n=51\end{array}$} & \multirow{2}{*}{$P \dagger$} & \multirow{2}{*}{$95 \% \mathrm{Cl}$} & \multicolumn{2}{|c|}{ Reaction time (sec) } \\
\hline & & & & & & Adolescents & Adults \\
\hline How long has it taken you to fall asleep each night? & $13.9 \pm 9.2$ & $14.5 \pm 8.6$ & $13.6 \pm 9.8$ & 0.660 & $-3.167-4.971$ & 0.061 & 0.477 \\
\hline $\begin{array}{l}\text { What time have you usually gotten up in the } \\
\text { morning? }\end{array}$ & $9.2 \pm 2.2$ & $9.3 \pm 1.4$ & $9.1 \pm 2.6$ & 0.711 & $-0.794-1.160$ & 0.722 & 0.987 \\
\hline $\begin{array}{l}\text { How many hours of actual sleep did you get at } \\
\text { night? }\end{array}$ & $7.7 \pm 1.3$ & $7.6 \pm 1.4$ & $7.8 \pm 1.3$ & 0.645 & $-0.717-0.446$ & 0.939 & 0.749 \\
\hline Cannot get to sleep within 30 minutes & $0.7 \pm 0.9$ & $0.9 \pm 1.0$ & $0.6 \pm 0.9$ & 0.053 & $-0.005-0.811$ & 0.168 & 0.127 \\
\hline $\begin{array}{l}\text { Wake up in the middle of the night or early } \\
\text { morning }\end{array}$ & $0.9 \pm 1.0$ & $1.5 \pm 1.1$ & $0.6 \pm 0.9$ & $<0.001$ & $0.377-1.242$ & 0.908 & 0.713 \\
\hline Have to get up to use the bathroom & $0.8 \pm 0.9$ & $1.1 \pm 0.9$ & $0.6 \pm 0.8$ & 0.007 & $0.152-0.938$ & 0.106 & 0.621 \\
\hline Cannot breathe comfortably & $0.1 \pm 0.2$ & $0.1 \pm 0.4$ & $0.1 \pm 0.1$ & 0.046 & $0.002-0.226$ & 0.014 & 0.693 \\
\hline Cough or snore loudly & $0.2 \pm 0.5$ & $0.3 \pm 0.7$ & $0.1 \pm 0.2$ & 0.020 & $0.040-0.470$ & 0.087 & 0.764 \\
\hline Feel too cold & $0.1 \pm 0.3$ & $0.1 \pm 0.3$ & $0.1 \pm 0.2$ & 0.255 & $-0.055-0.205$ & 0.158 & 0.077 \\
\hline Feel too hot & $0.7 \pm 1.0$ & $1.1 \pm 1.0$ & $0.4 \pm 0.8$ & 0.001 & $0.308-1.153$ & 0.190 & 0.642 \\
\hline Have bad dreams & $0.3 \pm 0.6$ & $0.4 \pm 0.7$ & $0.1 \pm 0.4$ & 0.012 & $0.073-0.566$ & 0.035 & 0.729 \\
\hline Have pain & $0.1 \pm 0.2$ & $0.1 \pm 0.1$ & $0.1 \pm 0.2$ & 0.794 & $-0.091-0.070$ & 0.734 & 0.673 \\
\hline \multicolumn{8}{|l|}{ During the past month... } \\
\hline $\begin{array}{l}\text {...how often have you taken medicine to help you } \\
\text { sleep? }\end{array}$ & $0.1 \pm 0.1$ & $0.1 \pm 0.1$ & $1 \pm 1$ & - & $-0.018-0.075$ & 0.743 & - \\
\hline $\begin{array}{l}\text {..how often have you had trouble staying awake } \\
\text { while driving, eating meals, or engaging in social } \\
\text { activity? }\end{array}$ & $0.1 \pm 0.4$ & $0.3 \pm 0.6$ & $0.1 \pm 0.2$ & 0.027 & $0.023-0.373$ & 0.494 & 0.830 \\
\hline $\begin{array}{l}\text {..how much of a problem has it been for you to } \\
\text { keep up enthusiasm to get things done? }\end{array}$ & $0.3 \pm 0.5$ & $0.4 \pm 0.6$ & $0.1 \pm 0.4$ & 0.009 & $0.075-0.507$ & 0.241 & 0.348 \\
\hline ...how would you rate your sleep quality overall? & $0.8 \pm 0.7$ & $0.9 \pm 0.7$ & $0.7 \pm 0.6$ & 0.219 & $-0.139-0.460$ & 0.471 & 0.376 \\
\hline
\end{tabular}

Questions 5-13 [scale: not during the past month (0), less than once a week (1), once or twice a week (2), three or more times a week (3)]; Questions 14-17 [scale: very good (0), fairly good (1), fairly bad (2), very bad (3)], RT = reaction time, $\dagger$ between groups, $95 \% \mathrm{Cl}=95 \%$ confidence Interval of the difference.

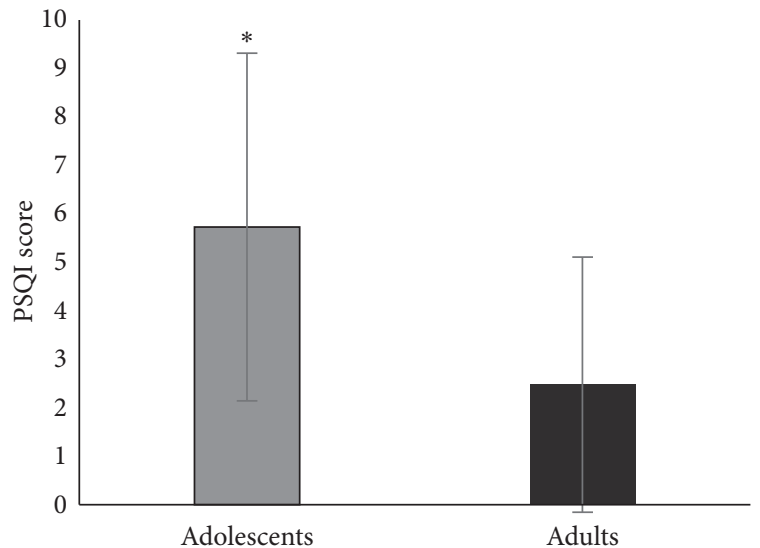

FIGURE 2: Relationship between adolescents and adults soccer players in PSQI score. $* P<0.001$.

loss is directly correlated with athletic injuries and/or " $f a$ tigue-related injuries" and this reduced amount of sleep is a direct, independent risk factor for injuries during exercise, diminishing the physical aspect of athletic performance [15].

4.1. Cardiopulmonary Fitness. Our results indicated a relationship among $V \mathrm{O}_{2 \max }$ and PSQI parameter "cannot breathe comfortably" and $\mathrm{VO}_{2}$ at anaerobic threshold (as a percent of $\left.V \mathrm{O}_{2 \max }\right)$, with parameters of PSQI "cannot get to sleep within 30 minutes," "cough or snore loudly," and PSQI score. These could be partly attributed to period and kind of training. The aerobic and anaerobic capacity are related to different competitive levels, playing positions, age groups, and interactions among these factors [1], while sleep deprivation is related to various factors that lower $V \mathrm{O}_{2 \max }$, such as reduced submaximal strength [16]. In the present study, higher scores in variabilities of PSQI questionnaire were observed in athletes with lower $V \mathrm{O}_{2}$ in anaerobic threshold, as a percent of maximal uptake, compared to athletes with higher $V \mathrm{O}_{2}$ in anaerobic threshold. In agreement with our findings, Vanuxem et al. [17] reported sleep deprivation relate to muscle metabolism with elevated levels of lactic acid concentration in the blood and decreased ability to remove it during exercise. In addition, Taheri and Arabameri [6] reported that anaerobic power is not affected following onenight sleep deprivation.

Our data present that athletes were classified as good sleepers at the total PSQI score $(3.1 \pm 2.9)$ compared to previous studies where athletes were classified as poor sleepers when having score $>5.5$ in PSQI [3]. The PSQI is a questionnaire subjected to the participant's self-assessment of sleep quality [11] during the last 30 days and incorporates both qualitative and quantitative aspects. The athletes enrolled were recruited during their preparation period. Although the participants' subjective rate of overall sleep quality is satisfying (3.1 \pm 2.9$)$, PSQI scores display particular 


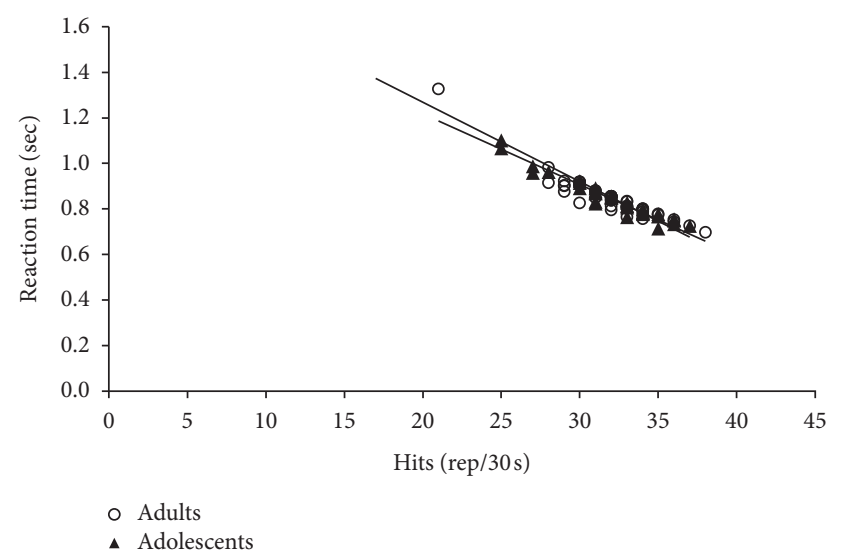

(a)

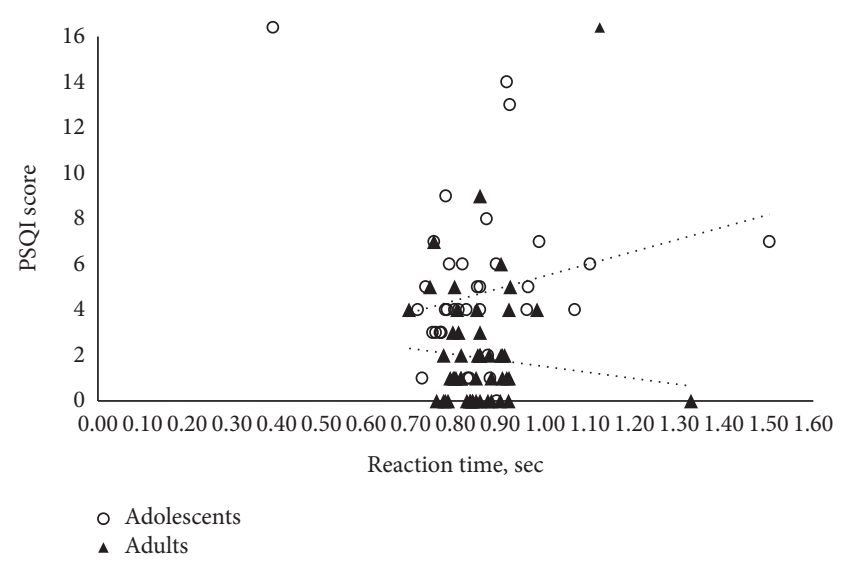

(b)

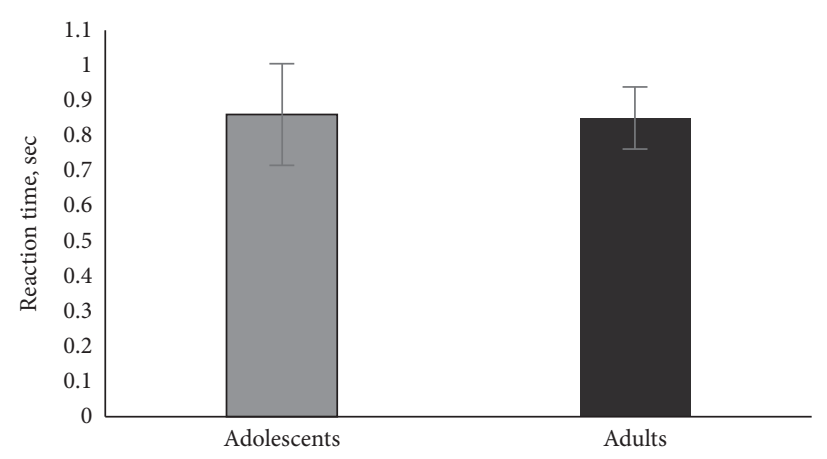

(c)

FIGURE 3: Relationship between reaction time and (a) hits (adults: $y=-0.031 x+1.8381, \quad R^{2}=0.8726, \quad P<0.001$; adolescents: $y=-0.0348 x+1.9653, R^{2}=0.9362, P<0.001$ ), (b) PSQI score (adults: $y=-2.6294 x+4.1389, \quad R^{2}=0.0126, P=0.265 ;$ adolescents: $\left.y=5.3768 x+0.1151, R^{2}=0.1663, P=0.046\right)$, and (c) age group.

sleep disturbances between the reaction time and PSQI parameters such as "cannot breathe comfortably," "have bad dreams," and ". . enthusiasm to get things done." Difficulties in breathing during sleep, such as PSQI parameter "cannot breathe comfortably", have been classified as sleep-related breathing disorders (SDB), which comprise a group of disorders from habitual snoring to obstructive sleep apnea (OSAS). Symptoms range from snore to periodic episodes of apnea in terms of breathing. Interestingly, the most prevalent manifestation of SDB is not disordered breathing like snoring, but excessive sleepiness, indicating the correlation between sleep breathing and cognition [18]. Hence, snoring is not innocent at all, for it is capable of initiating a pathophysiological cascade from events, like intermittent hypoxia, to diminished sleep quality $[19,20]$ and athletic performance.

According to Yoshitaka et al. [21], teenage athletes with SDB had higher heart rate in sleep compared to non-SDB athletes. SBD in athletes, with no clinical manifestations developed, could disturb the balance between the sympathetic and parasympathetic activity in ways that potentially may lead to adverse cardiovascular complications [22]. In the present study, it was shown that athletes with PSQI score $>5.5$ displayed slower recovery of HR during the first minutes of recovery stage compared to athletes with lower score (PSQI score $<5.5$ ). This chronotropic incompetence at recovery stage during exercise reflects the sympathetic and parasympathetic activity. In agreement with our previous findings [12], sleep deprivation results in instability of the autonomic nervous system, which is associated with endothelial dysfunction and sympathetic induced vasoconstriction. The main causative factor, for chronotropic incompetence, was proposed to be impaired cardiovascular autonomic function resulting from structural down regulation of cardiac $\beta$-receptors and/or altered baroreflex setpoint. Relevant studies by Costa et al. [23] enhanced this notion by providing evidence about athletes' chronobiology and environmental aspects in association with sleep and autonomic features.

4.2. Perceptual Ability Test. The correlation between variables of PSQI and PAT indicates of a broader association between quality and patterns of sleep and cognitive performance during exercise. Decreased performance and recovery for athletes [24] and deficits in attention and vigilance [25] have been attributed to poor sleep. During rapid eye movement sleep (REM) sleep, apneic episodes are exacerbated [26], making its complications, including restless dreaming, more prominent. Dreams are most common in REM [27], in which they tend to be more vivid, bizarre, and aggressive, as well as more memorable [28]. The PSQI 
parameter "have bad dreams" constitutes an additional indicator of poor quality of sleep, correlated with decreased perceptual ability. Since participants claim to have bad dreams, it is possible that they are awakened during REM sleep, resulting in sleep fragmentation and deprivation. Although it cannot be determined in the present study whether sleep deprivation is total or spatial, cognitive performance is adversely affected in both conditions, in terms of diminished attention span, decision-making ability, and reaction time [29].

Furthermore, athletes report less "...enthusiasm to get things done," which correlated with less reaction time in PATest. A low motivation in, e.g., training, perhaps due to daytime somnolence or not optimal recovery, indicates the necessity to reduce energy expenditure, as the stressful stimuli are inversely associated with physical activity [30]. This further undermines the preservation of muscle mass because of the reduction in training work load itself. Another candidate etiologic model for lack of motivation observed comprises the affected vigilance and motor coordination, as further neurocognitive complications of SDB [31]. Impaired attention/vigilance could either cover or be enhanced by amotivation and therefore loss for willingness in participating in athletic activities. Moreover, affected motor coordination concerns motor skill learning specifically in the consolidation phase [32], which in turn signifies lower scores in perceptual ability tests (PATest) due to a rather physical etiology.

4.3. Visual Stimulation and Motor Skills. Motor skills can become quite complex in fast-paced activities, like soccer, since the information from the surroundings flows in rapid and multidirectional streams. In such cases, athletes rely more on their visual processing skills and, thus, hone them with training protocols, such as stroboscopic vision perturbation [33]. It is worth noting that perturbation of visual process enhances perceptual-motor tasks, in contrast to its elimination, due to increased attentional allocation and faster reaction times [34]. Despite the fact that lack of motivation can be attributed to various reasons, the impact upon sports performance and athletes' perceptual abilities remains the same. The consequences become more apparent notably in competitive periods, in which stress and its effects mentioned above act synergistically, further undermining mental clarity.

4.4. Age and Body Composition. Our results presented relationship between age and body composition compared to PSQI score and selected variables of PSQI questionnaire (Table 1). Adolescents claimed to be poorer sleepers according to their PSQI scores, whereas their body composition was significantly more optimal. Thus, the diminished sleep quality and quantity in this age group could be attributed to factors regardless of body composition. According to Vitale et al. [35], the evergrowing prevalence of smartphones and other electronic devices in young adults are related to sleep deprivation and/or poor sleep quality, while the use of electronic devices has been associated with less sleep at night, probably because the light produced by electronic devices may disrupt circadian rhythms by suppressing melatonin, resulting in the inability to fall asleep at a reasonable time [36]. Sleep-wake cycle is subjected to circadian rhythm which, in contrary to popular belief, differs in puberty and adulthood. Melatonin in puberty is secreted comparatively later than in adulthood [37]. Due to this social misconception, adolescents are faced with delayed sleep phase, worsening their quality and quantity [38]. The disruption of sleep-wake cycle has been shown to reserve detrimental consequences, even in adolescents, by hindering the neuroplastic capability of honing social and cognitive skills [39].

Furthermore, sleep fragmentation is responsible for the disruption of the hypothalamic-pituitary-adrenal (HPA) axis, elevating cortisol levels [40]. Steroid hormones (testosterone, cortisol/corticosterone) affect the nocturnal catabolic debt conditions and they appear to be associated with increased adipose body mass in humans, which in turn diminishes performance in exercise due to suboptimal body composition [41], besides cognitive decline because of sleep deprivation. Cortisol enhances the activity of catecholamines and, hence, the SNS activity. Hypercortisolemia enhances arousal and vigilance up to a specific level in athletes [42], whereas, in excess levels, the benefits are reversed [43]. Hence, sleep deprivation does impact not only immunity, but also neuronal hubs' organization, signifying that the immune system is mutually related to brain functions [44].

4.5. Limitations. In our study, there were some limitations. The nocturnal polysomnography, as a gold standard for the diagnosis of sleep disordered breathing, and the chronotype, factor that influences athletes' sleep, were not evaluated. Color blindness, which is common in men as it affects approximately one in twelve (8\%) [45], was not assessed in the present study. The possibility of trouble of seeing red and green colors during PATest, leading to false lower scores, cannot be excluded. Moreover, the possible involvement of immune and pro-inflammatory markers was not assessed in the present study, as it seems to drive sleep-wake cycle based on maturation stage [46].

\section{Conclusion}

To sum up, sleep parameters, indicative of suboptimal sleep quality, were associated with lower reaction times, principally in adolescents, after exhaustive exercise. Sleep disturbances were associated with declines in perceptual ability's domains. Perceptual ability, which requires sustained attention, vigilance, and motor coordination, is often negatively affected by restricted sleep. It is suggested to inform athletes, regardless of age, about strategies of sleep hygiene, to prevent the detrimental effects of sleep deprivation in perceptual ability, athletic performance, and recovery. 


\section{Data Availability}

The data are available on request.

\section{Conflicts of Interest}

The authors declare that they have no conflicts of interest.

\section{References}

[1] M. Slimani, H. Znazen, B. Miarka, and N. L. Bragazzi, "Maximum oxygen uptake of male soccer players according to their competitive level, playing position and age group: implication from a network meta-analysis," Journal of Human Kinetics, vol. 66, no. 1, pp. 233-245, 2019.

[2] J. Costa, P. Figueiredo, F. Nakamura, V. Rago, A. Rebelo, and J. Brito, "Intra-individual variability of sleep and nocturnal cardiac autonomic activity in elite female soccer players during an international tournament," PLoS One, vol. 14, Article ID e0218635, 2019.

[3] V. Stavrou, G. D. Vavougios, F. Bardaka, E. Karetsi, Z. Daniil, and K. I. Gourgoulianis, "The effect of exercise training on the quality of sleep in national-level adolescent finswimmers," Sports Medicine-Open, vol. 5, p. 34, 2019.

[4] E. Miro, M. C. Cano-Lozano, and G. Buela-Casal, "Electrodermal activity during total sleep deprivation and its relationship with other activation and performance measures," Journal of Sleep Research, vol. 11, no. 2, pp. 105-112, 2002.

[5] D. Wlodarczyk, P. Jaskowski, and A. Nowik, "Influence of sleep deprivation and auditory intensity on reaction time and response force," Perceptual and Motor Skills, vol. 94, pp. 101-112, 2002.

[6] M. Taheri and E. Arabameri, "The effect of sleep deprivation on choice reaction time and anaerobic power of college student athletes," Asian Journal of Sports Medicine, vol. 3, no. 1, pp. 15-20, 2012.

[7] A. Andrade, G. G. Bevilacqua, D. R. Coimbra, F. S. Pereira, and R. Brandt, "Sleep quality, mood and performance: a study of elite Brazilian volleyball athletes," Journal of Sports Science \& Medicine, vol. 15, pp. 601-605, 2016.

[8] M. Thomas, H. Sing, G. Belenky et al., "Neural basis of alertness and cognitive performance impairments during sleepiness. I. Effects of $24 \mathrm{~h}$ of sleep deprivation on waking human regional brain activity," Journal of Sleep Research, vol. 9, no. 4, pp. 335-352, 2000.

[9] V. T. Stavrou, K. Astara, Z. Daniil et al., "The reciprocal association between fitness indicators and sleep quality in the context of recent sport injury," International Journal of Environmental Research and Public Health, vol. 17, no. 13, p. $4810,2020$.

[10] S. Voutselas, V. Stavrou, S. Zouridis, G. D. Vavougios, K. I. Gourgoulianis, and V. Voutselas, "The effect of sleep quality in sherpani col high camp everest," Respiratory Physiology \& Neurobiology, vol. 269, Article ID 103261, 2019.

[11] E. Perantoni, P. Steiropoulos, D. Siopi et al., "Validation of the Greek version of Pittsburg sleep quality questionnaire in a sleep lab population," European Respiratory Journal, vol. 40, p. 903, 2012.

[12] V. Stavrou, A. K. Boutou, G. D. Vavougios et al., "The use of cardiopulmonary exercise testing in identifying the presence of obstructive sleep apnea syndrome in patients with compatible symptomatology," Respiratory Physiology \& Neurobiology, vol. 262, pp. 26-31, 2019.
[13] F. Perroni, E. Mol, A. Walker et al., "Reaction time to visual stimulus in firefighters and healthy trained subjects: a preliminary comparative study," The Open Sports Sciences Journal, vol. 11, no. 1, pp. 69-77, 2018.

[14] M. Lastella, G. E. Vincent, R. Duffield et al., "Can sleep be used as an indicator of overreaching and overtraining in athletes?" Frontiers in Physiology, vol. 9, p. 436, 2018.

[15] M. Chennaoui, P. J. Arnal, F. Sauvet, and D. Léger, "Sleep and exercise: a reciprocal issue?" Sleep Medicine Reviews, vol. 20, pp. 59-72, 2015.

[16] D. W. Hill, D. O. Borden, K. M. Darnaby, and D. N. Hendricks, "Aerobic and anaerobic contributions to exhaustive high-intensity exercise after sleep deprivation," Journal of Sports Sciences, vol. 12, no. 5, pp. 455-461, 1994.

[17] D. Vanuxem, M. Badier, C. Guillot, S. Delpierre, F. Jahjah, and P. Vanuxem, "Impairment of muscle energy metabolism in patients with sleep apnoea syndrome," Respiratory Medicine, vol. 91, no. 9, pp. 551-557, 1997.

[18] S. Javaheri, F. Barbe, F. Campos-Rodriguez et al., "Sleep Apnea: types, mechanisms, and clinical cardiovascular consequences," Journal of the American College of Cardiology, vol. 69, no. 7, pp. 841-858, 2017.

[19] P. McNamara, D. McLaren, and K. Durso, "Representation of the self in REM and NREM dreams," Dreaming, vol. 17, no. 2, pp. 113-126, 2007.

[20] P. McNamara, D. McLaren, D. Smith, A. Brown, and R. Stickgold, "A "jekyll and hyde" within: aggressive versus friendly interactions in REM and non-REM dreams," Psychological Science, vol. 16, no. 2, pp. 130-136, 2005.

[21] I. Yoshitaka, K. Hitomi, K. Etsushi et al., "Prevalence and significance of sleep disordered breathing in adolescent athletes," ERJ Open Research, vol. 5, no. 1, p. 00029, 2019.

[22] J. S. Floras, "Sleep apnea and cardiovascular disease," Circulation Research, vol. 122, no. 12, pp. 1741-1764, 2018.

[23] J. A. Costa, J. Brito, F. Y. Nakamura, E. M. Oliveira, O. P. Costa, and A. N. Rebelo, "Does night training load affect sleep patterns and nocturnal cardiac autonomic activity in high-level female soccer players?" International Journal of Sports Physiology and Performance, vol. 14, no. 6, pp. 779-787, 2019.

[24] S. Mazza, J. L. Pépin, B. Naëgelé, J. Plante, C. Deschaux, and P. Lévy, "Most obstructive sleep apnoea patients exhibit vigilance and attention deficits on an extended battery of tests," European Respiratory Journal, vol. 25, no. 1, pp. 75-80, 2005.

[25] V. Deary, J. G. Ellis, J. A. Wilson, C. Coulter, and N. L. Barclay, "Simple snoring: not quite so simple after all?" Sleep Medicine Reviews, vol. 18, no. 6, pp. 453-462, 2014.

[26] I. Kritikou, M. Basta, A. N. Vgontzas et al., "Sleep apnoea and the hypothalamic-pituitary-adrenal axis in men and women: effects of continuous positive airway pressure," European Respiratory Journal, vol. 47, no. 2, pp. 531-540, 2016.

[27] P Alhola and P Polo-Kantola, "Sleep deprivation: impact on cognitive performance," Neuropsychiatric disease and treatment, vol. 3, no. 5, pp. 553-567, 2007.

[28] M. Alzoubaidi and B. Mokhlesi, "Obstructive sleep apnea during rapid eye movement sleep," Current Opinion in Pulmonary Medicine, vol. 22, no. 6, p. 545, 2016.

[29] J. C. Basso and W. A. Suzuki, "The effects of acute exercise on mood, cognition, neurophysiology, and neurochemical pathways: a review," Brain Plasticity, vol. 2, no. 2, pp. 127-152, 2017. 
[30] M. A. Stults-Kolehmainen and R. Sinha, "The effects of stress on physical activity and exercise," Sports Medicine, vol. 44, no. 1, pp. 81-121, 2014.

[31] G. Foussias and G. Remington, "Negative symptoms in schizophrenia: avolition and occam's razor," Schizophrenia Bulletin, vol. 36, no. 2, p. 359, 2010.

[32] V. Di Salvo, R. Baron, H. Tschan, F. Calderon Montero, N. Bachl, and F. Pigozzi, "Performance characteristics according to playing position in elite soccer," International Journal of Sports Medicine, vol. 28, no. 3, p. 222, 2007.

[33] A. Beavan, L. Hanke, J. Spielmann et al., "The effect of stroboscopic vision on performance in a football specific assessment," Science and Medicine in Football, 2020.

[34] S. J. Bennett, S. J. Hayes, and M. Uji, "Stroboscopic vision when interacting with multiple moving objects: perturbation is not the same as elimination," Frontiers in Psychology, vol. 9, p. $1290,2018$.

[35] K. C. Vitale, R. Owens, S. R. Hopkins, and A. Malhotra, "Sleep hygiene for optimizing recovery in athletes: review and recommendations," International Journal of Sports Medicine, vol. 40, no. 8, pp. 535-543, 2019.

[36] J. Owens, "Insufficient sleep in adolescents and young adults: an update on causes and consequences," Pediatrics, vol. 134, no. 3, pp. e921-e932, 2014.

[37] D.-J. Dijk and J. F. Duffy, "Circadian regulation of human sleep and age-related changes in its timing, consolidation and EEG characteristics," Annals of Medicine, vol. 31, no. 2, pp. 130-140, 1999.

[38] M. H. Hagenauer, J. I. Perryman, T. M. Lee, and M. A. Carskadon, "Adolescent changes in the homeostatic and circadian regulation of sleep," Developmental Neuroscience, vol. 31, no. 4, pp. 276-284, 2009.

[39] K. Astara, D. Siachpazidou, G. D. Vavougios et al., "Sleep disordered breathing from preschool to early adult age and its neurocognitive complications: a preliminary report," Sleep Science, 2021.

[40] L. Kubin, "Neural control of the upper airway: respiratory and state-dependent mechanisms," Comprehensive Physiology, vol. 6, pp. 1801-1850, 2016.

[41] M. Dattilo, H. K. M. Antunes, A. Medeiros et al., "Sleep and muscle recovery: endocrinological and molecular basis for a new and promising hypothesis," Medical Hypotheses, vol. 77, no. 2, pp. 220-222, 2011.

[42] S. Venkataraman, S. Vungarala, N. Covassin, and V. K. Somers, "Sleep apnea, hypertension and the sympathetic nervous system in the adult population," Journal of Clinical Medicine, vol. 9, no. 2, p. 591, 2020.

[43] M. Ezzati, A. D. Lopez, A. Rodgers, S. Vander Hoorn, and C. J. Murray, "Selected major risk factors and global and regional burden of disease," The Lancet, vol. 360, no. 9343, pp. 1347-1360, 2002.

[44] L. Marshall and J. Born, "Brain-immune interactions in sleep," International Review of Neurobiology, vol. 52, pp. 93-131, 2002.

[45] B. Wong, "Points of view: color blindness," Nature Methods, vol. 8 , no. 6 , p. $441,2011$.

[46] F. Pérez de Heredia, M. Garaulet, S. Gómez-Martínez et al., "Self-reported sleep duration, white blood cell counts and cytokine profiles in European adolescents: the HELENA study," Sleep Medicine, vol. 15, no. 10, pp. 1251-1258, 2014. 